\title{
Lengua y diversidad: herramientas digitales y literatura fuera del canon en la clase de español
}

\author{
Mailén Abril Salminis ${ }^{1}$ \\ Julieta Tosoroni ${ }^{2}$
}

\begin{abstract}
Resumo
Apresentamos uma proposta didática para o espanhol como língua estrangeira, baseada na problematização da categoria do cânone literário. Acreditamos que, através da literatura, é possível implicar uma multiplicidade de conhecimentos culturais e identitários, além dos aspectos formais da língua. 0 texto literário permite trabalhar todos aspectos e habilidades da língua (ESCOBAR, 2007), e também se torna um meio de interação entre a cultura própria e a alheia (VASCONCELO, 2006). Ao mesmo tempo, acreditamos que a literatura nos permite refletir sobre diferentes problemas sociais, e ainda mais quando estes são comuns a diferentes sociedades contemporâneas. É por isso que optamos por abordar, em diálogo com a questão do cânone, 0 problema da discriminação baseada na diversidade sexual. Essa ligação é possibilitada pelo uso de um quadro digital, com a ferramenta Padlet. Por meio desse recurso, se apresentam algumas atividades que favorecem a leitura, a escrita e o intercâmbio entre pares, em uma visão construtivista do ensino e aprendizagem. Assim, pretende-se avaliar o escopo das ferramentas digitais, seu potencial e seu impacto na educação (COLL, 2005), a fim de gerar conhecimentos duradouros e significativos (MAGGIO, 2012).
\end{abstract}

Palavras-chave: Espanhol língua estrangeira. Ferramentas digitais. Literatura fora do cânone.

\section{Resumen}

Presentamos una propuesta didáctica para la clase de español como lengua extranjera a partir de la problematización de la categoría de canon literario. Creemos que a través de la literatura es posible implicar una multiplicidad de saberes culturales e identitarios, más allá de los aspectos formales de la lengua. El texto literario permite trabajar todos los aspectos y destrezas de la lengua (ESCOBAR, 2007), y también se torna un medio de interacción entre la cultura propia y la ajena (VASCONCELO, 2006). Al mismo tiempo, creemos que la literatura permite reflexionar sobre diferentes problemáticas sociales, y más aún cuando estas son comunes a las distintas sociedades contemporáneas. Es por ello que elegimos indagar, en diálogo con la cuestión del canon, en la problemática de la discriminación por diversidad sexual. Este entrecruzamiento se hace posible gracias al diseño de una pizarra digital, con la herramienta Padlet. A través de este recurso se presentan algunas actividades que privilegian la lectura, la escritura y el intercambio entre pares, diseñadas con la modalidad de enseñanza mediante tareas (MELERO ABADÍA, 2004). Así, se pretende valorar el alcance de las herramientas digitales, sus potencialidades y su impacto sobre la educación (COLL, 2005) en busca de generar saberes duraderos y significativos (MAGGIO, 2012)

Palabras-chave: Español lengua extranjera. Herramientas digitales. Literatura fuera del canon.

La línea de cultura se ha quebrado, y también lo ha hecho con ella el orden temporal sucesivo. La simultaneidad y la mezcolanza han ganaao la partida: los canales se intercambian, las manifestaciones cultas, las populares y las de masas dialogan y no lo hacen en régimen de sucesión, sino bajo la forma de un cruce que acaba por tornarlas inextricables (RENAUD, 1995, p. 14).

\footnotetext{
${ }^{1}$ Mestranda em Letras: Linguagens e Representações (Universidad Estadual de Santa Cruz). Licenciada em Letras Modernas (Universidad Nacional de Córdoba).

${ }^{2}$ Graduanda em Letras Modernas (Universidad Nacional de Córdoba).
}

LínguaTec, Instituto Federal de Educação, Ciência e Tecnologia do Rio Grande do Sul, Bento Gonçalves 


\section{Introdução}

Presentamos una propuesta didáctica para la enseñanza del español como lengua extranjera que aborda, de manera transversal y a partir de textos literarios, la problemática de la discriminación por diversidad sexual. Partimos de la noción de "enseñanza poderosa" (MAGGIO, 2012), desde la cual se torna posible la construcción de conocimientos a partir del juego, la imaginación, la imitación de contextos lo más parecido posibles a distintos ámbitos de la realidad, en los que se produce la ruptura o desequilibrio cognitivo, generando saberes duraderos y significativos.

Optamos por el enfoque comunicativo para la enseñanza de español como lengua extranjera y, partiendo de este, diseñamos nuestra propuesta a partir de la modalidad de enseñanza mediante tareas. Esta modalidad busca organizar las actividades de aprendizaje a partir de la realidad del aula, incorporando la noción de comunicación como proceso (MELERO ABADÍA, 2004). Para ello, socializamos el diseño de una herramienta digital en la que se proponen diversas actividades que privilegian la lectura, la producción escrita y la interacción entre los sujetos comprometidos en la situación de enseñanza-aprendizaje.

El enfoque comunicativo para las lenguas extranjeras considera el desarrollo de la competencia cultural como un aspecto fundamental de la competencia comunicativa a través de habilidades lingüísticas, y entiende la capacidad de comunicarse como la capacidad de interactuar. Es en este marco que elegimos diseñar una propuesta privilegiando textos literarios, ya que seguimos a Escobar (2007) quien afirma que “[...] el material literario, por su diversidad, permite trabajar todos los aspectos y destrezas de la lengua y enfoques" (p. 18); a Chaves (2014), para quien el uso de distintos géneros literarios en las clases de español puede funcionar como herramienta pedagógica motivacional para el estudio de la lengua y sus culturas; y a Vasconcelo (2006), que explica que el objetivo de aprendizaje de una lengua no es sólo la habilidad lingüística, sino también “descubrir los sentimientos y las pautas culturales compartidos por los hablantes nativos de esa lengua" (p. 145).

Al abordar una temática que tiene que ver con las relaciones sociales y con las representaciones que se construyen en torno a ellas, resulta imposible no pensar en una construcción conjunta de saberes a partir de la problematización, la mirada crítica y la 
reflexión. Para ello se hace necesario un proceso en el que se conjuguen otras experiencias con la propia cosmovisión, y en este marco podemos pensar la literatura como "un medio de comunicación entre la concepción cultural propia y la de otras personas" (VASCONCELO, 2006, p. 149).

Por otra parte, y en diálogo con la cuestión de lo diverso y de las múltiples -y todas legítimas- posibilidades de existencia, abordamos la noción de canon en la literatura, partiendo del supuesto de que la decisión acerca de qué expresiones culturales/sociales/artísticas pueden ser o no canónicas es social, y por lo mismo se va modificando en el tiempo, con el influjo de diversos factores.

El recurso digital utilizado es la "pizarra digital" Padlet (https://padlet.com/), que ofrece la potencialidad de utilizar al mismo nivel recursos gráficos, textuales y audiovisuales. También permite plantear recorridos flexibles, donde no existe un orden preestablecido sino que el estudiante o el docente pueden definirlo. Se trata de una herramienta dinámica, de fácil apropiación y utilización y también accesible desde distintos dispositivos3.

Por otro lado, la potencialidad hipertextual del recurso permite activar diversos procesos cognitivos, diferentes a los propios de otros formatos como el texto en papel y las secuencias rígidas de lectura, y también procesos productivos a la hora de generar una mayor interacción con el contenido seleccionado. La hipertextualidad permite además trabajar en la intertextualidad, dimensión necesaria para sumar voces frente a una temática compleja como es la discriminación por diversidad sexual. Abordar esta temática en espacios educativos formales tendrá sentido si se lo hace desde distintas perspectivas, oyendo diversas voces, leyendo diferentes tipos de textos y contemplando los contextos específicos en donde la propuesta se lleve a cabo. Por ello escogemos una herramienta digital que nos permite trabajar con múltiples tipos de textos, plasmados en variados soportes y formatos. Se ponen a disposición de los estudiantes y docentes tanto instrumentos para promover la discusión -recursos textuales y audiovisuales-, como espacios de intercambio de opiniones -foros y espacios para comentar-.

\footnotetext{
3 La versión de Padlet para celulares permite trabajar sin conexión.
} 
Los estudiantes explorarán libremente la pizarra digital en donde encontrarán textos literarios y no literarios, videos, imágenes, propuestas de acciones concretas, música, distintas formas de expresión artística, etc., y harán su propio recorrido para llevar a cabo su reflexión y plasmarla en un producto final. En este punto, destacamos que la utilización de esta herramienta digital no busca solamente promover una manera diferente de enseñar, sino que es a partir de ella que podemos abordar la enseñanza de español como lengua extranjera a partir de un mayor acercamiento a situaciones comunicativas reales y cercanas a los aprendices de la lengua. Este es uno de los procedimientos propios de la modalidad de enseñanza mediante tareas, que pretende que las situaciones de comunicación sean efectivamente reales y no meras representaciones, y sucedan dentro del contexto áulico. En nuestra propuesta, la realización de un producto final nos permite fomentar el aprendizaje autónomo en los alumnos así como también incluir el desarrollo de las cuatro destrezas hablar, leer, escribir y escuchar- de forma integrada.

David Nunan, citado por Pilar Melero Abadía, define a las tareas como "una parte del trabajo en clase que hace que los alumnos comprendan, manipulen, produzcan y se comuniquen en la lengua meta centrando su atención más en el significado que en la forma" (MELERO ABADÍA, 2004, p. 96). En otras palabras, los contenidos desarrollados son aplicados a tareas determinadas, que permiten la realización de un proyecto mayor consensuado entre alumnos y docente. De este modo, el dominio de la lengua es concebido no como un proceso de codificación y decodificación de mensajes, o como la memorización de un sistema de reglas formales, sino como un instrumento para la comunicación, para lo que resulta necesario incluir situaciones comunicativas en el mismo proceso de aprendizaje.

Entonces, las actividades diseñadas a partir de este enfoque buscan que la lengua sea efectivamente empleada en el aula, con una participación activa de los alumnos. En este sentido, a partir del trabajo en la pizarra digital Padlet se posibilitarán recorridos diversos, se generarán puestas en común y debates entre los estudiantes, contribuyendo tanto a la práctica de la oralidad y la escritura en la lengua meta como a la reflexión sobre una problemática social actual y necesaria como es la discriminación por diversidad sexual.

Cabe destacar que la propuesta está dirigida a estudiantes de español como lengua extranjera adultos o adolescentes, que ya tengan un alto grado de competencia en la 
lengua, para que les sea posible comprender un vocabulario complejo y diversidad de tipologías textuales. La realización del producto final puede ser considerada como actividad.

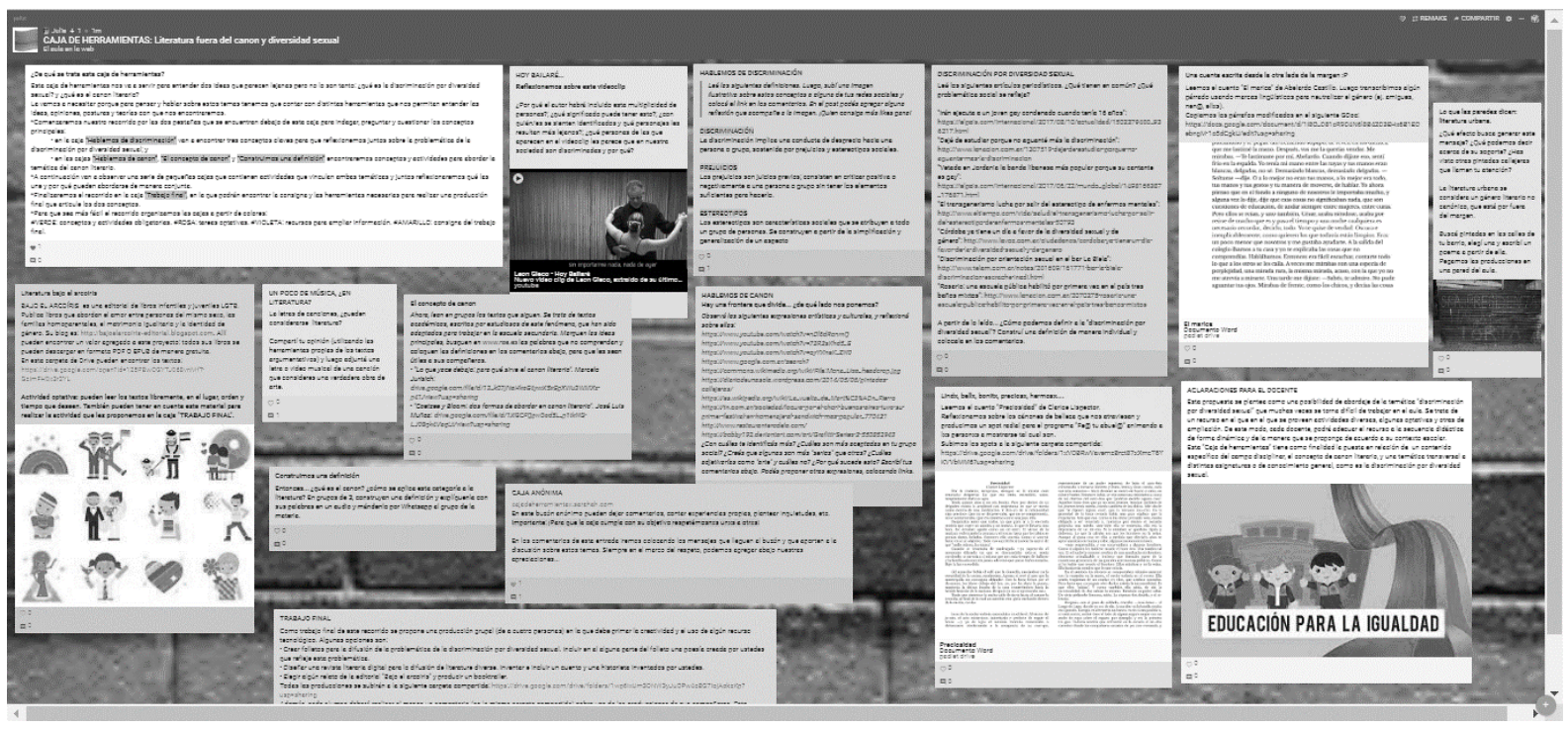

Figura 1. Vista general de la pizarra digital.

Fuente: Elaborada por las autoras.

\section{Fundamentación teórica}

La tecnología ha provocado tales transformaciones socioculturales en las últimas décadas que el trabajo con herramientas digitales es algo que se da naturalmente: ya no podemos pensar nuestras prácticas sin su utilización. Ello sucede porque no sólo es una forma conceptual de relacionarnos con el mundo, sino también de formar nuestra subjetividad. No podemos obviar la tecnología, está ahí, condicionándonos y acompañándonos en todo momento (PEIRONE, 2015). Sin embargo, a la hora de proponer una herramienta digital para la enseñanza, resulta central que su utilización sea realmente significativa en relación a la temática a trabajar y al grupo de alumnos al que va dirigido. Del mismo modo, debe permitir abordar los contenidos y construir un conocimiento diferente al que hubiera resultado sin el uso del recurso tecnológico, ya que como explica Coll,

no es en las TIC sino en las actividades que llevan a cabo profesores y estudiantes gracias a las posibilidades de comunicación, intercambio, acceso y procesamiento de la información que les ofrecen las TIC, donde hay que buscar las claves para comprender y valorar el alcance de su impacto sobre la educación escolar (2005, p. 5). 
Nuestra propuesta se encuentra con esa necesidad por distintos motivos. En primer lugar, por lo dificultoso que resultaría abordar un tema como la discriminación por diversidad sexual desde un modelo de clase tradicional. Si bien se trata de una problemática que no es nueva en nuestras sociedades, resulta relevante abordarla en la coyuntura actual y en la cotidianeidad de nuestras prácticas. Es por ello que resulta necesario trabajar con acceso a la red, para tener contacto con producciones literarias y no literarias actuales, en vigencia, que por una cuestión de temporalidad -y de decisiones editoriales- no están presentes en los materiales impresos que se comercializan para la enseñanza de la lengua.

En segundo lugar, y pensando en el ámbito disciplinar de la literatura, la necesidad de incorporar herramientas digitales tiene que ver con la misma noción de canon literario, que se pretende problematizar. Lo que en cada momento histórico la sociedad entiende como canónico está regido, entre otros factores, por las leyes de mercado. Y es lo que estas leyes recomiendan lo que se encuentra disponible o no en formato papel. Como ya mencionamos, esto vale para los materiales educativos. El resto de las producciones no canónicas -de la literatura, por ejemplo- recorren otros circuitos, entre los que predomina internet. Uno de los objetivos de esta propuesta es que los estudiantes conozcan y accedan a estos otros soportes no tradicionales para la literatura.

Por último, creemos que la posibilidad de abordar la problemática del canon y la temática de la diversidad sexual con el recurso a la hipertextualidad, donde los estudiantes puedan acceder a otras páginas a partir de links, oír simultáneamente una canción relacionada con el tema mientras leen o escriben, compartir producciones y respuestas en tiempo real, proponer ellos mismos algunos contenidos, permite construir saberes mucho más significativos y duraderos a los que pueden surgir en otro tipo de propuestas más tradicionales.

En este sentido, creemos que no basta con simplemente incluir herramientas digitales a nuestras clases, sino que deben ser los mismos contenidos a trabajar y los objetivos que nos proponemos los que deben exigir el uso de nuevas tecnologías, a las que, como sostiene Maggio, hay que "reconocerlas, entenderlas y generar propuestas que las integren y las reconstruyan con sentido didáctico" (2012, p. 92). La autora agrega que para construir "saberes en tiempos de la web" es necesario enseñar a navegar por ella, a buscar información, a contrastar las fuentes, a construir criterios de selección y análisis. Estos son 
aprendizajes que se desarrollan en el marco de las nuevas tecnologías de la información y que ameritan el acompañamiento del docente.

Por otro lado, creemos que la presente propuesta logra potenciar algunas de las habilidades que Anijovich y Mora (2012) atribuyen a los jóvenes, ya que permite la decodificación de diferentes tipos de lenguajes y la creación de nuevas producciones a partir de otras, en donde las características propias de las nuevas tecnologías se resignifican en una propuesta pedagógica. Sumado a esto, las autoras insisten en la necesaria búsqueda y selección de recursos potentes para provocar la curiosidad de los alumnos, pero además hablan de la necesidad de enseñar cómo leer imágenes. Es a partir de ello que esta propuesta permite realizar lecturas y puesta en relación no sólo de textos escritos, sino también de imágenes y videos, lo que supone un ejercicio de uso didáctico de la tecnología, más allá de los contenidos específicos que se abordan.

\section{Contenidos y objetivos}

Como ya hemos mencionado, la propuesta presentada vincula una problemática social como la discriminación por diversidad sexual con el concepto de "canon literario", en el marco de la enseñanza del español como lengua extranjera.

Los dos ejes temáticos interrelacionados están articulados necesariamente a través de dispositivos tecnológicos con acceso a internet, ya que este es uno de los únicos medios a través de los que se puede acceder a producciones literarias no canónicas. Entonces, la herramienta también se propone como una plataforma de recopilación y difusión de este tipo de literatura, que aborda específicamente la temática de la diversidad sexual. Aquí se encuentra la relación entre ambos contenidos: se trata de cuerpos, sexualidades, formas de relacionarse que están en los márgenes, que juegan en la línea de lo canónico y lo no canónico, así como sucede con la literatura y otras expresiones culturales.

A partir de lo dicho anteriormente, formulamos nuestros objetivos para la propuesta didáctica. Para ello, planteamos no una jerarquía sino un paralelismo entre los contenidos propios de la enseñanza del español como lengua extranjera, y la temática transversal abordada. Este paralelismo puede verse también plasmado en la herramienta multimedial 
diseñada, tanto en la organización espacial de textos, imágenes y recursos, como en la propuesta de recorrido y actividades planteada.

Esperamos que con la pizarra digital los estudiantes logren:

- Desarrollar habilidades comunicativas en español, tanto en comprensión como en producción;

- Problematizar el concepto de canon en literatura y conocer otros formatos y soportes;

- Concebir al texto literario en su potencialidad crítica y de denuncia social;

- Conversar sobre las distintas interpretaciones y apreciaciones de textos literarios leídos;

- Involucrarse en la problemática y la discusión acerca de la discriminación por diversidad sexual;

- Intercambiar experiencias personales o cercanas en relación a esta temática;

- Reflexionar sobre las representaciones sociales en cuanto a lo canónico y lo no canónico;

- Identificar discursos sociales que reproducen prejuicios y estereotipos sobre la sexualidad.

\section{Descripción y explicación de la propuesta}

La propuesta didáctica que presentamos tiene como soporte el software Padlet. Esta herramienta, dispuesta al modo "pizarra" o "mural" virtual, permite un trabajo colaborativo, online y de fácil utilización, a su vez, cuenta con la posibilidad de ingresar a su plataforma desde diversos dispositivos electrónicos sólo con tener acceso a internet.

En su página web, Padlet se define como: “Fácil e intuitivo, inclusivo, colaborativo, flexible, portátil y seguro". Consideramos que la manera más adecuada de generar un espacio educativo y de reflexión sobre una temática como la escogida debe estar vehiculizada a través del diálogo. En este sentido, al ser Padlet una herramienta accesible y de fácil utilización para todos, permite y sirve de marco para una comunicación fluida de las propuestas entre docente y alumnos. 
Por otro lado, al pretender abordar literatura no canónica, resulta indispensable contar con una herramienta que nos permita mostrar en un mismo nivel tanto obras literarias como otro tipo de expresiones artísticas no consideradas dentro de lo académicamente reconocido como arte (literatura urbana, grafitis, canciones, etc.). Trabajar con literatura fuera del canon implica también trabajar fuera de los circuitos tradicionales de distribución de la literatura, por ende, internet se transforma en una herramienta útil para tener acceso expresiones artísticas que no llegan al mercado editorial tradicional.

En la pizarra virtual diseñada es posible observar cuatro "niveles" de atención:

1- “¿De qué se trata esta pizarra virtual?". En esta sección se introduce el material y se brinda la guía para su abordaje. Aquí se especifica un sistema de colores que utilizamos para determinar qué tipo de actividades encontrarán en el muro (color verde: conceptos y actividades obligatorias; rosa: tareas optativas; violeta: recursos para ampliar información y amarillo: consigna del trabajo final). Esto permite andamiar el recorrido del alumno en la herramienta y, a su vez, habilita una libertad de búsqueda e investigación sobre ella.

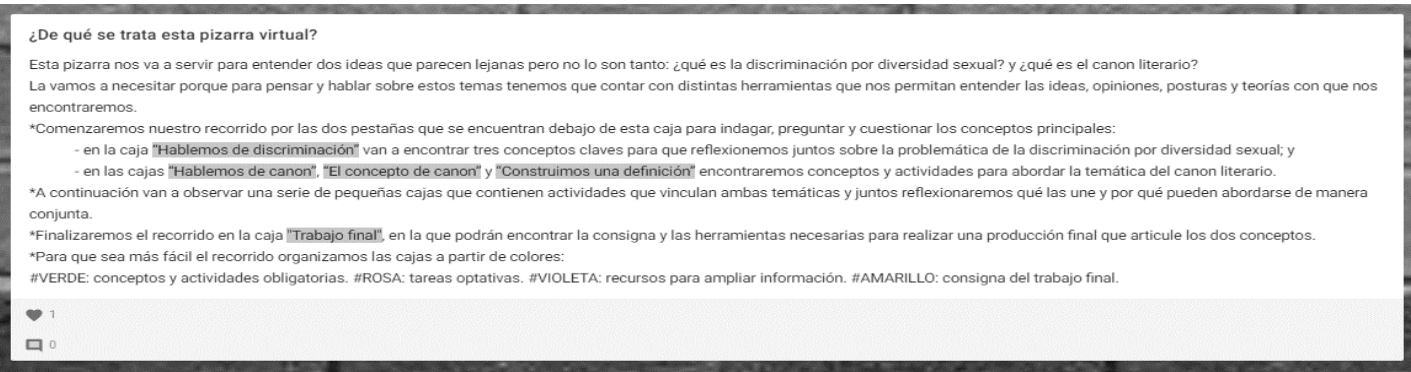

Figura 2. ¿De qué se trata la pizarra virtual? Fuente: Elaborada por las autoras.

2- "Hablemos de discriminación" y "Hablemos de canon". Ambas cajas se encuentran en un mismo nivel e introducen los conceptos y actividades fundamentales para ingresar en los dos contenidos principales de la propuesta. 


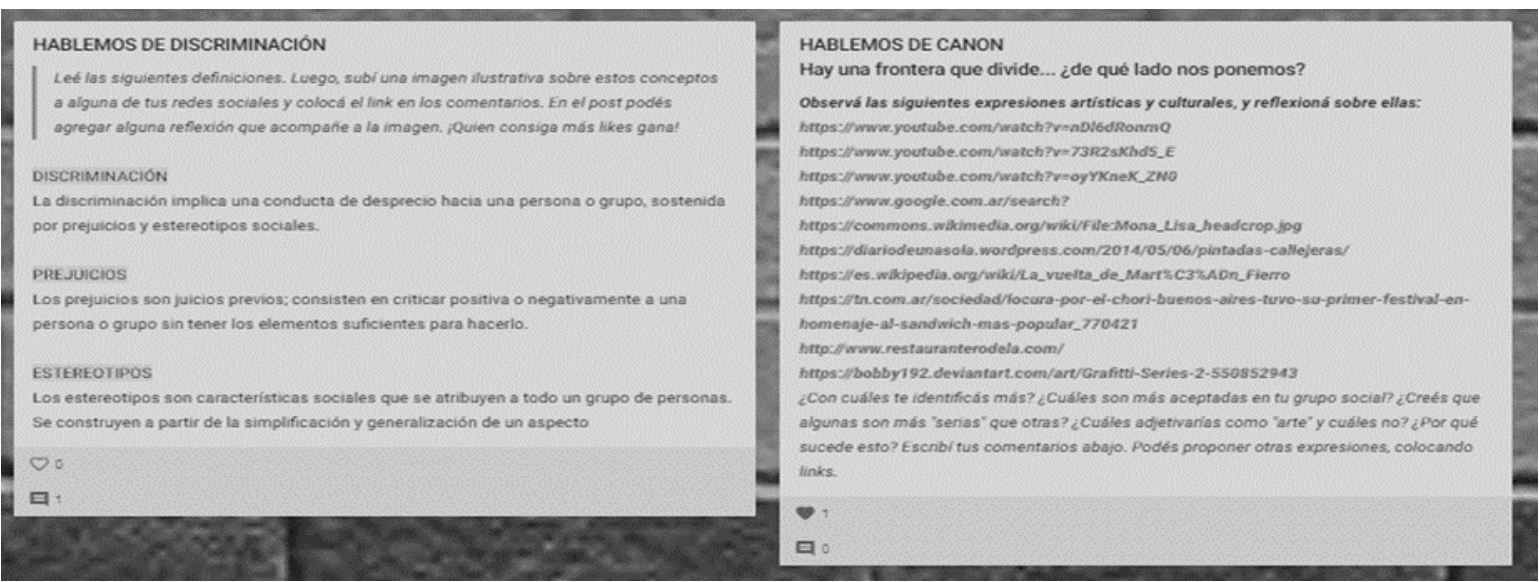

Figura 3. Hablemos de discriminación/Hablemos de canon.

Fuente: Elaborada por las autoras.

3- Más abajo se encuentran diferentes cajas que proponen actividades que abordan las temáticas por separado u otras que las vinculan. Algunas de estas actividades, a modo de ejemplo, son:

- "Hoy bailaré...": A partir de la visualización de un videoclip (https://youtu.be/PAFrZ8FWgrc), se propone sensibilizar a los alumnos sobre la temática de la discriminación. Las conclusiones pueden colocarse en el Padlet a modo de comentario y/o ponerse en común en una instancia de debate.

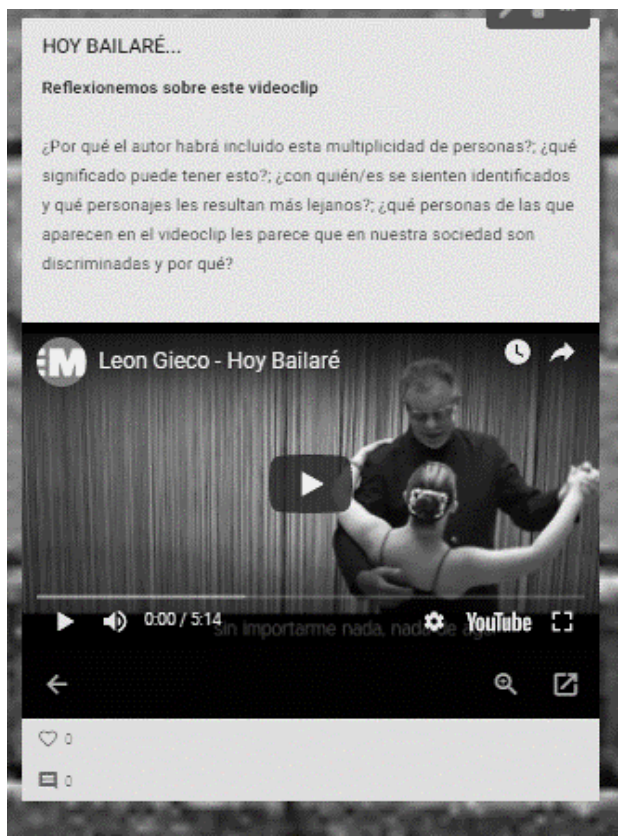

Figura 4. Hoy bailaré.

Fuente: Elaborada por las autoras.

LínguaTec, Instituto Federal de Educação, Ciência e Tecnologia do Rio Grande do Sul, Bento Gonçalves 
- "Discriminación por diversidad sexual": Se propone la lectura de textos periodísticos que relatan diversos hechos de discriminación por diversidad sexual en todo el mundo. Se solicita construir una definición propia sobre este tipo de discriminación y colocarla en los comentarios.

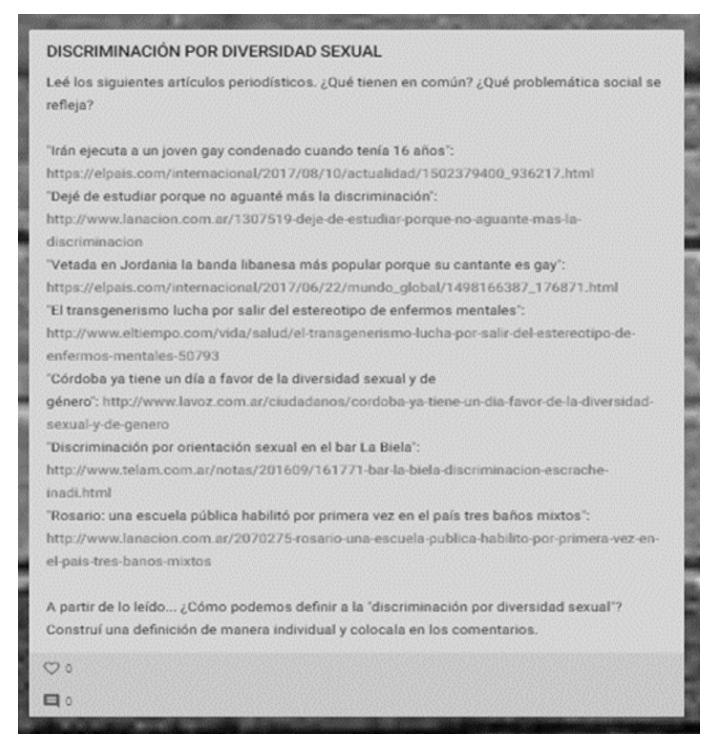

Figura 5. Discriminación por diversidad sexual. Fuente: Elaborada por las autoras

- "Lo que las paredes dicen: literatura urbana". En esta actividad se presenta una fotografía de un grafiti relacionado con la temática de la diversidad sexual y se plantean algunas preguntas interpretativas. Luego, se propone a la literatura urbana como un género no canónico, y se solicita a los estudiantes que busquen otros ejemplos y escriban un poema a partir de lo encontrado. 


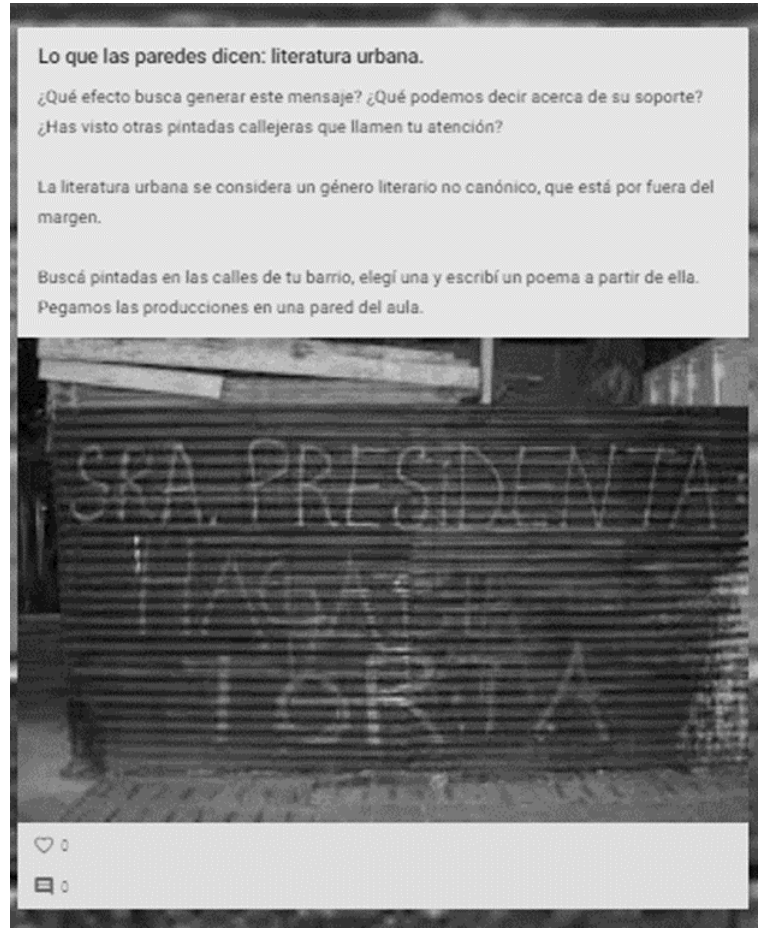

Figura 6. Lo que las paredes dicen.

Fuente: Elaborada por las autoras.

- "Literatura bajo el arcoiris": Se propone la lectura de relatos publicados por la editorial "Bajo el arcoiris", primera editorial infantil y juvenil LGBT de la Argentina y de América Latina, que tiene sus libros editados en e-book y se pueden descargar desde internet (https://bajoelarcoiriseditorial.blogspot.com/). Son textos literarios que tratan explícitamente la temática de la diversidad sexual, y el corpus seleccionado por la editorial tiene como eje la problemática de la discriminación. Esta es una actividad optativa, en la que los alumnos elegirán un relato para leer en los tiempos, espacios y modalidades que prefieran, propiciando la práctica de “lectura por placer". 


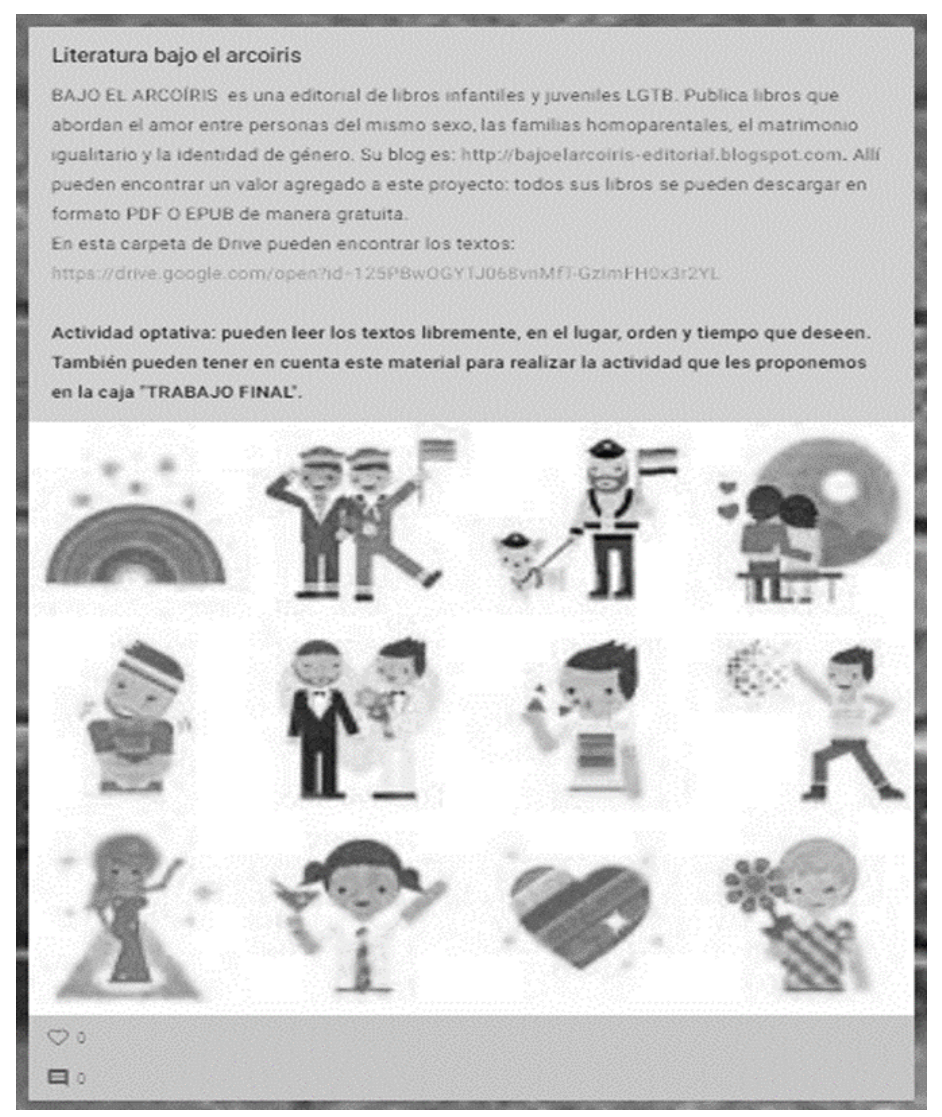

Figura 7. Literatura bajo el arcoiris.

Fuente: Elaborada por las autoras.

4- En un último nivel se encuentra la entrada "Trabajo final" que está pensada para cerrar el proceso de aprendizaje a través de la creación de un producto, bajo la premisa de que el aprendizaje sólo tiene lugar si existe la necesidad real de comunicar algo a alguien y de que, si no hay motivación, el aprendizaje falla (MELERO ABADÍA, 2004). Entonces, se proponen distintas opciones, como crear folletos virtuales para la difusión de la problemática de la discriminación por diversidad sexual; diseñar una revista literaria digital para la difusión de literatura diversa; o elegir algún relato de la editorial "Bajo el arcoiris" y producir un booktrailer. Para realizar cualquiera de estas actividades, los alumnos deberán: apropiarse de conocimientos a partir de un trabajo cooperativo, propiciar una actitud reflexiva en torno a la temática para su posterior difusión e idear una manera de hacer llegar esta discusión al resto de la comunidad para generar conciencia sobre el tema.

Es necesario advertir, siguiendo a Coll (2005, p. 9), que "cada sistema simbólico tiene sus propias restricciones, fruto de los signos con los que opera [...] y de las reglas de composición o sintaxis que utiliza para combinarlos". En este punto se torna necesario 
reconocer las limitaciones que tiene este tipo de herramienta, como por ejemplo la imposibilidad de organizar la información de manera jerárquica, ya que no se pueden crear pestañas o nuevas ventanas dentro de la misma herramienta. Para solventar esta dificultad, incluimos entradas en las que, mediante un link, se puede acceder a otras páginas y aplicaciones para ampliar la información, o para plasmar las producciones propias. Esto posibilita integrar distintas herramientas como Drive, Whatsapp, Facebook, E-book, Instagram, Youtube, entre otras, y en las que las producciones de los alumnos deben adoptar diversos formatos: texto, audio, video, imagen, etc.

Proponemos pensar el Padlet como una de las herramientas que crean condiciones inéditas para operar con la información, a diferencia de los sistemas simbólicos clásicos (COLL, 2005), ya que supone una estructuración diferente y original de los contenidos y actividades (MAGGIO, 2012). Además, a partir de Anijovich y Mora (2012), creemos que se trata de una propuesta que permite estructurar el contenido de manera que los alumnos cumplan un rol activo: agregar comentarios, elegir cuáles consignas resolver, qué textos leer, qué opción de producto final crear. Las autoras resaltan lo positivo de acordar con los estudiantes las metas de aprendizaje. Los diferentes segmentos del Padlet permiten guiar una secuencia didáctica planteada en varias clases según cómo vaya realizándose el proceso de aprendizaje de los alumnos en instancias de debate áulico y aprendizaje cooperativo.

Padlet permite lo que Kress (2003) explica como la reconfiguración de la página a partir de las permisibilidades y organizaciones de la pantalla. Como hemos dicho, los cambios en las disposiciones textuales que genera este recurso también promueven procesos cognitivos diversos de apropiación de la información. Por último, al pensar en la posibilidad de la creación de un producto final por parte de los alumnos a partir del trabajo con herramientas digitales, entrelazamos la enseñanza al proceso creador. A partir de la enseñanza mediante tareas (MELERO ABADÍA, 2004), es necesario superar la concepción de aprendizaje como fin en sí mismo y tender hacia experiencias significativas de uso real de la lengua, con una intención comunicativa que trascienda el aula. 


\section{A modo de conclusión}

Con esta propuesta didáctica pretendemos realizar un aporte al campo de enseñanza del español como lengua extranjera, atendiendo a una temática poco abordada en las clases de lenguas, y con una metodología que creemos acertada para la efectiva adquisición de la lengua como instrumento de comunicación.

Creemos que abordar la enseñanza de la lengua desde la literatura resulta enriquecedor en relación con los aspectos culturales de la lengua, y más aun abordando una problemática social que nos involucra a todos, independientemente de la lengua que hablemos.

Los contenidos propuestos pueden ser trabajados también en vinculación con otras prácticas socioculturales que permitan indagar la noción de canon, así como en una perspectiva interdisciplinar -psicología, sociología, artes, historia, geografía, entre otras áreas.

Recuperamos la noción de "enseñanza poderosa" (MAGGIO, 2012), desde la cual se torna posible la construcción de conocimientos a partir del juego, la imaginación y la imitación, para generar saberes duraderos y significativos.

\section{Referencias}

ANIJOVICH, R.; MORA, S. Estrategias de enseñanza. Otra mirada al quehacer en el aula. Buenos Aires: Editorial Aique, 2012.

CHAVES, L. S. Coleção Cercanía Joven: aprenda Espanhol por meio da literatura. In Boletim PNLD 2015, Edições SM, 2014.

COLL, C. Psicología de la educación y prácticas mediadas por las tecnologías de la comunicación y la información. Una mirada constructivista. In: Revista Sinectica $N^{0} 25$. Universidad Jesuita de Guadalajara, 2005. Disponible en: https://www.redalyc.org/articulo.oa?id=99815899016. Acceso en: 30 sept. 2019.

ESCOBAR, A. La literatura como recurso multifuncional en la clase de ELE. In: PATO, E.; DOBAO, A. F. (Orgs.). La enseñanza del español como lengua extranjera en Quebec. Montreal: Université de Montréal/Tinkuy 7, 2007. 
KRESS, G. El Alfabetismo en la era de los nuevos medios de comunicación. Málaga: Ediciones Aljibe, 2003.

MAGGIO, M. Enriquecer la enseñanza. Los ambientes con alta disposición tecnológica como oportunidad. Buenos Aires: Paidós. 2012

MELERO ABADÍA, P. De los programas nocional-funcionales a la enseñanza comunicativa. In: SÁNCHEZ, J. y SANTOS, I. (eds.), Vademécum para la formación de profesores. Enseñar español como segunda lengua (L2)/ lengua extranjera (LE), Madrid: SGEL, pp. 689-714.

PEIRONE, F. Desafectación, audacia y diversión. La cultura juvenil actual, el gran desafío de la escuela del siglo XXI. 2015. Disponible en: http://fernandopeirone.com.ar/escritos/educacion/. Acceso en: 30 sept. 2019.

RENAUD, Alain. L'image: de l'économie informationelle à la pensée visuelle. In: Reseaux $\mathrm{N}^{0}$ 74, Paris, 1995.

VASCONCELO, Nélida Beatriz. La literatura: un espacio curricular a considerar en ELE. In: Enseñanza del español como lengua extranjera en Argentina. Experiencia y reflexiones. Rosario: Editora Universidad Nacional de Rosario, 2006, pp. 145-150.

Data de submissão: 01/10/2019. Data de aprovação: 15/10/2019. 